\title{
Impact of RASSF1A gene methylation on the metastatic axillary nodal status in breast cancer patients
}

\author{
EVA JEZKOVA $^{1,2}$, PAVOL ZUBOR $^{1,3}$, KAROL KAJO $^{4}$, MARIAN GRENDAR $^{5}$, KAROL DOKUS $^{3}$, \\ MARIAN ADAMKOV ${ }^{2}$, ZORA LASABOVA $^{1}$, LUKAS PLANK $^{6}$ and JAN DANKO ${ }^{3}$
}

\author{
${ }^{1}$ Department of Oncology, Biomedical Center Martin; ${ }^{2}$ Department of Histology and Embryology, Jessenius Faculty of \\ Medicine, Comenius University in Bratislava; ${ }^{3}$ Department of Obstetrics and Gynaecology, Jessenius Faculty of Medicine, \\ Martin University Hospital, 03601 Martin; ${ }^{4}$ St. Elizabeth Cancer Institute Hospital, 81250 Bratislava; ${ }^{5}$ Bioinformatic \\ Unit, Biomedical Center Martin, Jessenius Faculty of Medicine, Comenius University in Bratislava; ${ }^{6}$ Department \\ of Pathological Anatomy, Jessenius Faculty of Medicine, Martin University Hospital, 03601 Martin, Slovakia
}

Received October 11, 2016; Accepted January 31, 2017

DOI: $10.3892 / \mathrm{ol} .2017 .6204$

\begin{abstract}
Hypermethylation of $\mathrm{CpG}$ islands is a hallmark of cancer and occurs at an early stage in breast tumorigenesis. To gain insight into the epigenetic switches that may promote and/or contribute to the initial neoplastic events during breast carcinogenesis, the present study focused on the DNA methylation profile of invasive breast carcinoma. The aim of the study was to evaluate the prognostic significance of Ras association domain family 1 isoform A (RASSF1A) promoter methylation status in operable breast cancer, and to analyze the utility of this biomarker regarding its association with metastatic and nonmetastatic axillary nodal status. For this purpose, formalin-fixed, paraffin-embedded tissue specimens from 116 breast cancer patients with known axillary nodal status were subjected to assessment of RASSF1A promoter methylation status by methylation-specific polymerase chain reaction (MSP) and methylation-sensitive high-resolution melting assay, and the results were subsequently validated by bisulfite sequencing. A multinomial logistic regression model was used to model the dependence of distinct levels of methylation status of the RASSF1A promoter on the nodal status. Promoter region $\mathrm{CpG}$ hypermethylation was identified by MSP in 97 (83.6\%) of 116 primary breast tumors, while hypermethylation of RASSF1A was confirmed by MS-HRM in 107 (92.2\%) of 116 cases of breast cancer. Based on the results of the multinomial logistic regression model, there was no significant difference between the frequency of RASSFIA promoter methylation and axillary lymph node status of patients in general. However, upon adjustment of $\mathrm{pN}$ stage, an association was identified between
\end{abstract}

Correspondence to: Professor Pavol Zubor, Department of Obstetrics and Gynaecology, Jessenius Faculty of Medicine, Martin University Hospital, Kollarova 4248/2, 03601 Martin, Slovakia E-mail: zubor@jfmed.uniba.sk

Key words: methylation, lymph node status, RASSF1A, methylation-specific polymerase chain reaction
pNO lymph node-negative status (without axillary metastases) and percentage of RASSF1A methylation in two groups of heterogeneous methylated alleles with $\leq 50 \%$ methylated $(\mathrm{P}<0.05)$ and $>50 \%$ methylated alleles $(\mathrm{P}<0.0001)$. If a patients' nodal status changes from $\mathrm{pN}$ - to $\mathrm{pN}+$ then the risk of having $>50 \%$ methylated alleles increases by $7 \%$. The present study revealed a specific phenomenon, suggesting that the presence of heterogeneous methylated alleles in the RASSF1A gene is significantly associated with lymph node-negative status in breast cancer patients. Furthermore, greater significance with negative axillary nodal status was observed with a higher level of heterogeneous methylated alleles in the RASSF1A gene.

\section{Introduction}

Malignant tumors belong to priority areas of concern of any responsible society and its scientific community. For decades, the most common malignant disease in female patients has been breast cancer (1). The pathological evaluation of benign and malignant breast lesions underwent remarkable changes with the introduction of molecular diagnostic methods, and thus, increased knowledge about the biological nature of individual lesions (2).

Mammary carcinoma is a cancer that most commonly affects women, and dissemination of tumor cells by the lymph-vascular pathway at an early stage of development is considered a decisive factor of mortality (3). An early diagnosis of breast carcinoma favors a better prognosis. Breast cancer, at a very early stage of its development, has already cell clones with such a severe genetic defect that can result in metastatic potential and formation of metastases in secondary sites $(4,5)$. In $\leq 30 \%$ of breast cancer patients diagnosed with distant metastasis, conventional treatment methods fail to stop the disease progressing, which suggests an early event of lymph node invasion $(5,6)$. Thus, the detection of occult invasion and lymph node metastasis prediction requires novel, and preferentially more sensitive, methods such as molecular genetics.

By using these methods, structural changes in different genes associated with alterations in the function of proteins can be observed. Such changes may alter or reduce the levels of certain gene protein products, including tumor-suppressor 
or metastatic-suppressor genes, thus leading to neoplasia or metastasis formation in secondary sites (7). Currently, part of the standard diagnostic tools monitoring breast carcinoma are biological markers with good informative value, including estrogen receptor (ER), progesterone receptor (PR) and lymph nodes status, which are important prognostic and predictive biomarkers (8). However, although the presence or absence of metastases in axillary lymph nodes is the strongest prognostic factor for patients with primary breast cancer, it only indirectly reflects the tendency of the cancer to spread (9).

Histological examination of axillary lymph nodes, including lymphatic mapping of metastatic spread of the disease, is essential for the detection or exclusion of any tumor cells in the node (10). False-negative examinations of lymph nodes may have severe clinical consequences for the patient. Based on false-negative results, regional lymphadenectomy or systematic chemotherapy is not indicated, and thus, lymph nodes affected by metastatic turnover change may result in untreated disease progression (11). For this reason, nodal status must be investigated more thoroughly than only by using conventional staining techniques of lymph nodes with hematoxylin and eosin, which could be inadequate (12). Currently, there are four standard methodological approaches for surgical identification of sentinel lymph nodes (SLNs): i) ${ }^{99 \mathrm{~m} T c-n a n o-}$ colloid lymphoscintigraphy; ii) blue color tracking methods such as Patent Blue V; iii) a combined method involving the use of both the above substances at the same time; and iv) a paramagnetic method using iron oxide nanoparticles (13).

However, there is still uncertainty and no optimal method for precise metastatic event detection, particularly at the level of micrometastases and isolated tumor cells. This assessment has been recently made by using immunohistochemistry and multilevel serial incision of lymph nodes (14). Axillary lymph node dissection (ALND) has traditionally been a routine component of the management of early breast cancer. The benefits of ALND include its impact on disease control (axillary recurrence and survival), its prognostic value and its role in treatment selection. However, the anatomic disruption caused by ALND may result in lymphedema, nerve injury and shoulder dysfunction, which compromise functionality and quality of life (15). ALND is the typical approach for women who have clinically palpable axillary nodes or positive nodes confirmed by methods such as ultrasound-guided fine needle aspiration. For patients who have clinically negative axillary lymph nodes, SLN biopsy is a method of staging the axilla with less morbidity than that of ALND (16). Logically, sentinel lymph node biopsy (SLNB) without ALND has been recommended as the standard procedure for the management of SLN-negative patients with early breast cancer; however, the efficiency of SLNB for SLN-positive patients remains unclear (16). Pathologists have limited time and ability to perform a precise node examination under surgery. However, the performance of nodal assessment several days prior to the main surgery is now available, and allows pathologists to have a detailed assessment of the lymphatic tissue, either performed as a fine needle aspiration biopsy or as a complete SNB (17-20).

Isolated tumor cells are clusters usually diagnosed by immunohistochemistry and molecular biology methods. It is considered that these cells have no metastatic activity, and the histopathological staging is designated as pNOmi in the regional lymph nodes (21). Currently, micrometastases and isolated tumor cells are undergoing renewed scientific focus in order to identify their prognostic value and clinical outcomes. In general, an urgent requirement to define their prognostic value by promoter methylation status assessment of the Ras association domain family 1 isoform $\mathrm{A}(R A S S F 1 A)$ gene in the affected nodes both at the level of micrometastases and macrometastases exists (22). Furthermore, these micrometastases can remain dormant for years prior to re emerging as incurable secondary tumors that are insensitive to adjuvant chemotherapies that were previously effective against the primary tumor (21). Further experimental analyses are required to investigate the precise function of RASSF1A methylation in breast cancer invasion and metastasis.

As hypermethylation of tumor-suppressor genes is consi dered an early event of breast carcinogenesis, the present study detected aberrant methylation of the tumor-suppressor and cancer-associated gene RASSF1A in order to identify its potential correlation with an early stage of axillary nodal affection, since hypermethylation of the RASSF1A gene promoter has been reported to be an early event of carcinogenesis and to participate in various gynecological neoplasia $(23,24)$, such as breast cancer $(25,26)$.

As hypermethylation is a transient and markedly sensitive event, the present study used rapid assays for the detection of small levels of heterogeneous methylated alleles in breast cancer patients based on a methylation-sensitive high-resolution melting (MS-HRM) technology and a methylation-specific polymerase chain reaction (PCR) (MSP) approach. These methods were applied to assess the possible role of RASSF1A gene hypermethylation in early axillary nodal affection in women with breast cancer.

\section{Materials and methods}

Clinical specimens. Formalin-fixed, paraffin-embedded tissue sections from 116 breast cancer patients operated on between June 2013 and June 2016 at the Department of Obstetrics and Gynaecology, Jessenius Faculty of Comenius University and University Hospital Martin (Martin, Slovakia) were evaluated. The histopathological data reflecting cancer biology, including lymph node involvement, were obtained from the medical database at the Department of Pathology, Jessenius Faculty of Comenius University and University Hospital Martin. All participants were of Caucasian origin and residents in the geographic area of Slovakia (Table I). The Regional Ethics Committee of Jessenius Faculty of Medicine (registered under IRB00005636 at the Office for Human Research Protection, USA Department of Health and Human Services) approved the present study protocol (code no. EK 1269/2013). Written informed consent was obtained from all patients.

Histopathological analysis. Tumor and lymph node specimens were fixed in formalin and embedded in paraffin; basic histological examination was performed on $4-5-\mu$ m-thick slides stained with hematoxylin and eosin. In selected cases, lymph nodes were stained immunohistochemically (cytokeratin 19) to detect potential isolated tumor cells or micrometastases. Classical morphological indicators such as tumor type and histological grade, were evaluated according 
Table I. Clinicopathological characteristics of the cohort $(n=116$ patients).

\begin{tabular}{|c|c|}
\hline Characteristic & Patients, n (\%) \\
\hline \multicolumn{2}{|l|}{ Age, years } \\
\hline$<50$ & $20(17.3)$ \\
\hline$\geq 50$ & $96(82.7)$ \\
\hline \multicolumn{2}{|l|}{ Stage } \\
\hline 1 & $65(56.0)$ \\
\hline 2 & $34(29.3)$ \\
\hline 3 & $7(6.0)$ \\
\hline 4 & $6(5.2)$ \\
\hline $\mathrm{X}$ & $4(3.5)$ \\
\hline \multicolumn{2}{|l|}{ Histological grade } \\
\hline 1 & $21(18.1)$ \\
\hline 2 & $42(36.2)$ \\
\hline 3 & $48(41.4)$ \\
\hline $\mathrm{X}$ & $5(4.3)$ \\
\hline \multicolumn{2}{|l|}{ Lymph node metastases } \\
\hline Positive & $52(44.8)$ \\
\hline Negative & $64(55.2)$ \\
\hline \multicolumn{2}{|l|}{ ER status } \\
\hline Positive & 95 (81.9) \\
\hline Negative & $21(18.1)$ \\
\hline \multicolumn{2}{|l|}{ PR status } \\
\hline Positive & $89(76.7)$ \\
\hline Negative & $27(23.3)$ \\
\hline \multicolumn{2}{|l|}{ HER-2 amplification } \\
\hline Positive & $23(19.8)$ \\
\hline Negative & $93(80.2)$ \\
\hline \multicolumn{2}{|l|}{ Molecular subtype } \\
\hline Luminal A (ER ${ }^{+}$and/or $\left.\mathrm{PR}^{+}, \mathrm{HER}-2^{-}\right)$ & $86(74.1)$ \\
\hline Luminal B $\left(\mathrm{ER}^{+}\right.$and/or $\left.\mathrm{PR}^{+}, \mathrm{HER}-2^{+}\right)$ & $10(8.6)$ \\
\hline Basal-like (ER-, PR $\left.{ }^{-}, \mathrm{HER}-2^{-}\right)$ & $8(6.9)$ \\
\hline HER-2 type (ER $\left.{ }^{-}, \mathrm{PR}^{-}, \mathrm{HER}-2^{+}\right)$ & $12(10.4)$ \\
\hline \multicolumn{2}{|l|}{ Tumor type } \\
\hline Ductal & $104(89.7)$ \\
\hline Lobular & $7(6.0)$ \\
\hline Other & $5(4.3)$ \\
\hline
\end{tabular}

ER, estrogen receptor; PR, progesterone receptor; HER, human epidermal growth factor receptor; $\mathrm{X}$, not determined/not available.

to the World Health Organization criteria and Nottingham grading modification $(27,28)$. The pathologic (p) stage of breast cancer takes into consideration the characteristics of the tumor $(\mathrm{T})$ and the presence of any lymph nodes metastases $(\mathrm{N})$ or distant organ metastases $(\mathrm{M})$. These major tumor characteristics were assessed according to the criteria of the latest tumor-node-metastasis classification (29). Biological parameters, including estrogen receptor (ER), progesterone receptor $(\mathrm{PR})$ and human epidermal growth factor receptor (HER)-2, were detected immunohistochemically, and their interpretation was based on the American Society of Clinical Oncology/College of American Pathologists criteria from 2010 and 2013 (30-32). Briefly, immunohistochemistry. For ER, PR and HER-2 was performed concurrently on serial sections with ready-to-use (RTU) reagents using an automated immunostainer Autosteiner Link 48 (Dako; Agilent Technologies, Inc., Santa Clara, CA, USA).

Primary ER (Flex Monoclonal Rabbit ER $\alpha$; clone EP1, RTU; cat. no. IR08461) and PR antibody (Flex Monoclonal Mouse; clone PgR636, RTU; cat. no. IS0683) were supplied by Dako; Agilent Technologies, Inc. Antigen retrieval was performed using EnVision ${ }^{\mathrm{TM}}$ Flex Target Retrieval High $\mathrm{pH}$ solution ( $\mathrm{pH} 9.0$ ) for $20 \mathrm{~min}$ at $97-98^{\circ} \mathrm{C}$ in a PT Link instrument (both Dako; Agilent Technologies, Inc.). Endogenous peroxidase activity was blocked by incubating sections with $3 \%$ hydrogen peroxide for $10 \mathrm{~min}$, followed by primary antibody incubation for $20 \mathrm{~min}$ at room temperature. The EnVision Flex/HRP High pH kit (cat. no. K8000; Dako; Agilent Technologies, Inc.) was used to visualize staining according to the manufacturer's protocol.

The immunohistochemistry for HER-2 was performed using a HercepTest ${ }^{\mathrm{TM}}$ Breast+Gastric kit (cat. no. SK001; Dako; Agilent Technologies, Inc.). Antigens were retrieved in HercepTest Epitope Retrieval Solution ( $\mathrm{pH}$ 6.0), using PT Link for $40 \mathrm{~min}$ at $97-98^{\circ} \mathrm{C}$. Sections were blocked for endogenous peroxidase in $3 \%$ hydrogen peroxide for $10 \mathrm{~min}$, and then incubated with the primary antibody for $30 \mathrm{~min}$ at room temperature. HercepTest Visualization reagents from the kit were used $30 \mathrm{~min}$ at room temperature according to the manufacturer's protocol.

Tumors were considered as ER and PR positive if $\geq 1 \%$ of neoplastic cells stained positively. HER-2-expressing tumors had to exhibit a $3+$ reaction in $\geq 10 \%$ of neoplastic cells to be considered positive. Cases with $2+$ reaction of HER-2 staining were considered as equivocal and were analyzed by fluorescent in situ hybridization to confirm or exclude HER-2 gene amplification. Briefly, slides were hybridized with probes to locus-specific identifier, HER2/neu and centromere 17 using the PathVysion HER-2 DNA Probe kit (Abbott Pharmaceutical Co. Ltd., Lake Bluff, IL, USA) according to manufacturer's protocol.

Definite positivity of HER-2 status in tumors was defined as a HER-2/chromosome enumeration probe 17 ratio of $\geq 2.0$ or an average HER- 2 copy number of $\geq 6.0$ signals per cell $(31,32)$.

DNA extraction and bisulfite modification. Paraffin sections of tissue were subjected to deparaffinization by incubation with an organic solvent (xylene) and a decreasing series of 96,80 and $70 \%$ ethanol solutions. Subsequently, the ethanol was removed from the sections by drying the samples at room temperature until the ethanol had evaporated completely. Tissues were suspended in $200 \mu \mathrm{l}$ of lysis buffer (Buffer AL) and digested using proteinase $\mathrm{K}$ (both Qiagen $\mathrm{GmbH}$, Hilden, Germany) for 3 days, or longer if necessary, at $56^{\circ} \mathrm{C}$. Subsequent genomic DNA extraction was performed using DNeasy Blood \& Tissue kit (Qiagen $\mathrm{GmbH}$ ) according to the manufacturer's recommendations. Bisulfite modification of 116 target DNA samples $(\leq 3-5 \mu \mathrm{g})$ was performed with the EpiTect Bisulfite kit (Qiagen $\mathrm{GmbH}$ ) according to the manufacturer's protocol with minor changes. Instead of incubating the columns for $5 \mathrm{~min}$ at $56^{\circ} \mathrm{C}$ 


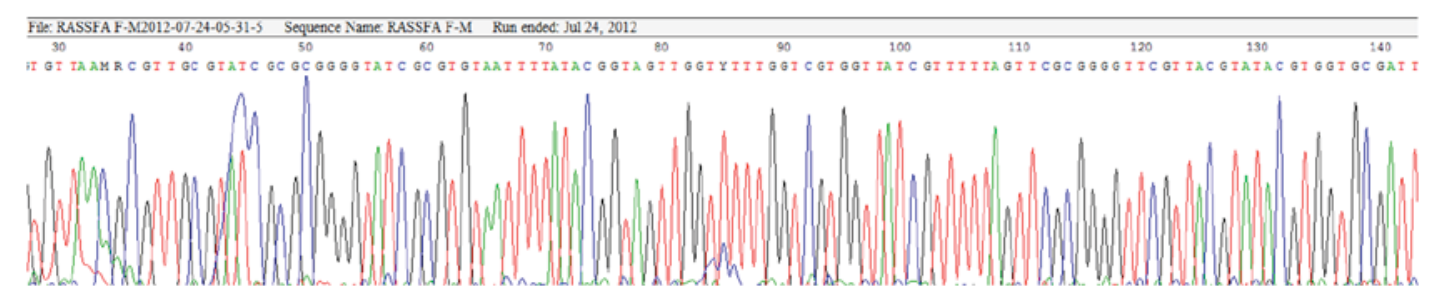

Figure 1. Electropherogram showing a region of the DNA sequence reamplified by methylation-specific polymerase chain reaction with a forward primer for the RASSF1A gene promoter region. Sequences were subjected to comparison with the AF132675.1 sequence in the GenBank database. The blue/black CG peaks in the gene represents the presence of methylation in the CpG islands RASSF1A, Ras association domain family 1 isoform A.

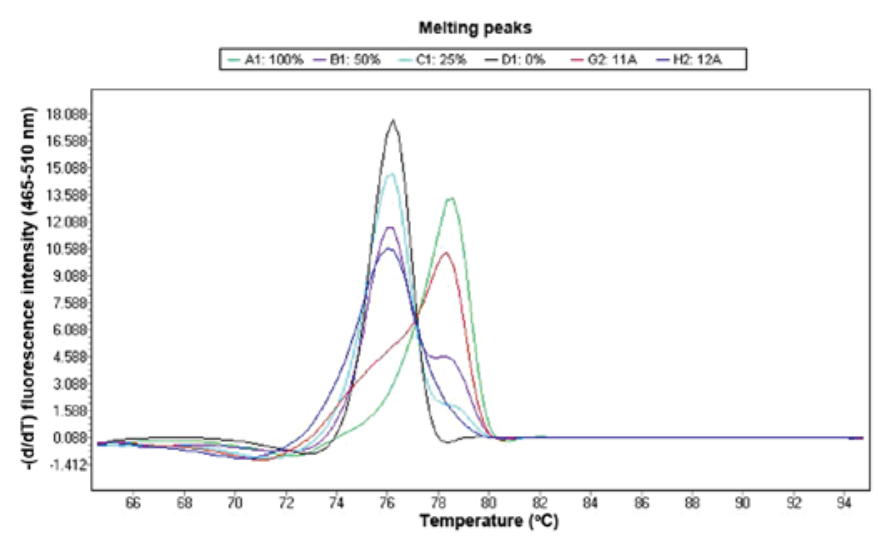

Figure 2. Melting peaks for hypermethylated RASSF1A gene promoter showing standards as $100 \%$ methylated alleles (green), $50 \%$ methylated alleles in a background of unmethylated DNA (purple), $25 \%$ methylated alleles in a background of unmethylated DNA (turquoise) and unmethylated control (black). Representative methylation profile of samples with $>50 \%$ methylated alleles, $11 \mathrm{~A}$ (red) and with unmethylated alleles as 12A (dark blue) is also shown.

in a heating block, the columns were incubated for $15 \mathrm{~min}$ at $56^{\circ} \mathrm{C}$ in a thermostat in the present study.

As positive (methylated) and negative (unmethylated) controls, commercially available EpiTect methylated and unmethylated controls (Qiagen $\mathrm{GmbH}$ ) were used, which contained $0.1 \mu \mathrm{g} / \mu \mathrm{l}$ methylated and fully unmethylated DNA, respectively.

MSP. The first step of MSP was performed with $2.0 \mu \mathrm{l}$ of bisulfite-modified DNA template in $25 \mu \mathrm{l}$ of reaction mixture containing $2.5 \mathrm{mmol} / 1 \mathrm{MgCl}_{2}, 10 \mathrm{pmol} / \mathrm{l}$ of each forward and reverse external primers, $0.5 \mathrm{mmol} / \mathrm{l}$ of each of the four deoxynucleotides and $2.5 \mathrm{mmol} / \mathrm{l}$ of 10X ReddyMix PCR buffer (ABgene; Thermo Fisher Scientific, Inc.). Negative-control samples without DNA target were included. The external primers used in first MSP step were forward, 5'-TTGAGT TGYGGGAGTTGGTAT-3' and reverse, 5'-CCCAAATAA AATCRCCACAAAAAT-3'. The amplification reaction was performed with a hot start at $95^{\circ} \mathrm{C}$ for $8 \mathrm{~min}$, followed by 45 cycles of denaturation at $95^{\circ} \mathrm{C}$ for $30 \mathrm{sec}$, annealing temperature for external primers of $60^{\circ} \mathrm{C}$ for $30 \mathrm{sec}$, extension at $72^{\circ} \mathrm{C}$ for $30 \mathrm{sec}$ and a final step of $8 \mathrm{~min}$ at $72^{\circ} \mathrm{C}$. In total, $9 \mu \mathrm{l}$ of each reaction were loaded onto a $1.5 \%$ agarose gel stained with Gel Red $^{\mathrm{TM}}$ (Biotium, Inc., Hayward, CA, USA) and visua lized under ultraviolet light. The PCR product for the external primer had a length of $198 \mathrm{bp}$. The second step of MSP was performed using $1 \mu \mathrm{l}$ of the PCR product (10-50 ng cDNA) obtained in the first step of the reaction with internal primers, diluted in a $25 \mu \mathrm{l}$ reaction volume. For methylated DNA targets, the following primers were used: Forward, 5'-GTG TTAACGCGTTGCGTATC-3' and reverse, 5'-AACCCCGCG AACTAAAAACGA-3'. For unmethylated DNA targets, the following primers were used: Forward, 5'-TTTGGTTGGAGT GTGTTAATGTG-3' and reverse, 5'-CAAACCCCACAAACT AAAAACAA-3'. The reamplification products were analyzed on a Gel $\operatorname{Red}^{\mathrm{TM}}$-stained agarose gel and subsequently validated by bisulfite sequencing.

Bisulfite sequencing. To validate the results from MSP, DNA sequencing was performed on PCR-reamplified MSP products. The PCR products were purified with the NucleoSpin Gel and PCR Clean-up kit (Macherery-Nagel, GmbH, Düren, Germany) according to the manufacturer's recommendations. The purified PCR products were amplified in a sequencing reaction with BigDye Terminator v1.1 Cycle Sequencing kit (Applied Biosystems; Thermo Fisher Scientific, Inc.) and subsequently purified on a Sepharose ${ }^{\mathrm{TM}}$ SigmaSpin Post-Reaction Clean-Up Column (Sigma-Aldrich; Merck KGaA, Darmstadt, Germany). The products were denatured and then analyzed by capillary electrophoresis in a 3500 Genetic Analyzer (Applied Biosystems; Thermo Fisher Scientific, Inc.). The resulting sequences were analyzed by using Chromas software 2.0 (Technelysium Pty Ltd., South Brisbane, Australia) and compared with the sequence of the gene RASSF1A (AF132675.1) in the GenBank database (https://www.ncbi.nlm.nih.gov/gene?Cmd=DetailsSe arch\&Term=11186) (Fig. 1).

MS-HRM. MS-HRM detected $\leq 1 \%$ methylated DNA in a background of unmethylated DNA. The technology is sensitive, inexpensive and thus likely to become an appropriate technique for a diagnosis of methylation of the RASSF1A gene in breast cancer patients as a predictor of bilateral nodal spread (33). To compare the sensitivity of detection of methylation by various methods, MS-HRM was used, since this method is able to define more precisely the extent of methylation in the sample than MSP (34). MS-HRM was conducted on a LightCycler ${ }^{\circledR} 480$ System (Roche Diagnostics, Basel, Switzerland). PCR products (5-10 ng cDNA) of the first step of MSP were diluted to the desired concentration in a $10 \mu \mathrm{l}$ reaction volume, and the standards were prepared by mixing methylated DNA $(0.1 \mu \mathrm{g} / \mu \mathrm{l})$ with unmethylated DNA $(0.1 \mu \mathrm{g} / \mu \mathrm{l})$ (both Qiagen $\mathrm{GmbH})$ to obtain 100, 50, 25 and 0\% methylated/unmethylated DNA dilutions (Fig. 2). MS-HRM was performed with the same internal primers as described earlier. MS-HRM was performed in a total volume of $10 \mu \mathrm{l}$ 


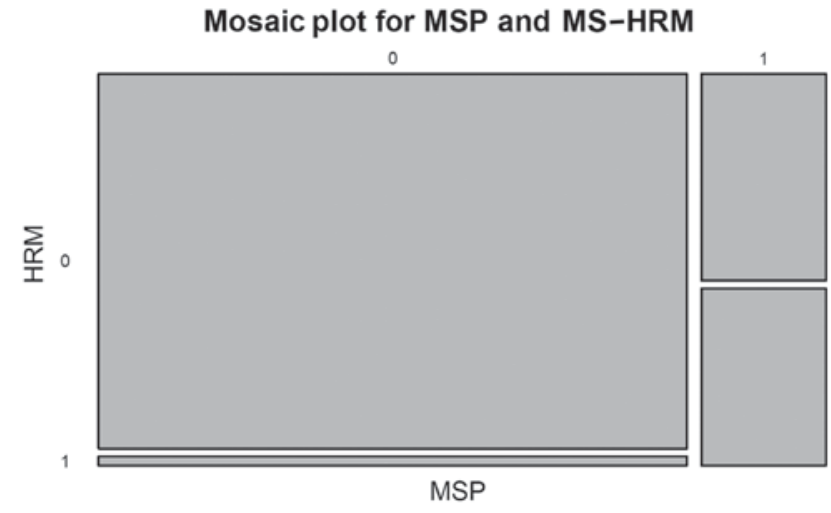

Figure 3. Compliance of the two methods used for detection of the methylation status of the Ras association domain family 1 isoform A gene: MSP and MS-HRM. To compare the two methods, the 4 levels of methylation obtained by MS-HRM were combined into two categories: $1, \leq 50 \%$ methylated and unmethylated alleles; $0,>50$ and $100 \%$ methylation statuses. In 3 cases, the samples considered to be 0 (methylated) by MSP were considered to be 1 (unmethylated) by MS-HRM. In 14 cases, the samples considered to be 0 (methylated) by MS-HRM were considered to be 1 (unmethylated) by MSP. The rectangular area represents the number of samples in the particular category. MSP, methylation-specific polymerase chain reaction; MS-HRM, methylation-sensitive high-resolution melting.

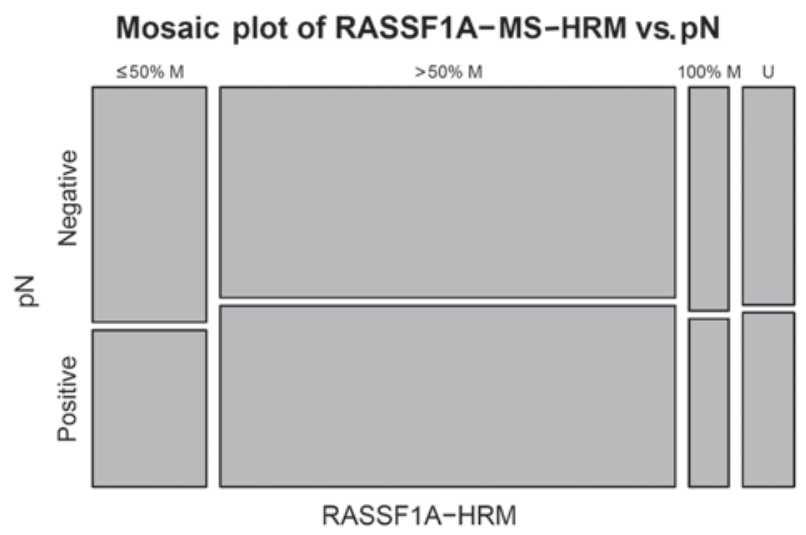

Figure 4. RASSF1A methylation profiles by MS-HRM in positive- or negative-pN status. The percentage of RASSF1A methylation had a range of 0 (unmethylated allele), $\leq 50,>50$ or $100 \%$. The rectangular area represents the number of samples in the particular category. pN, pathological node; MS-HRM, methylation-sensitive high-resolution melting; M, methylated; U, unmethylated; RASSF1A, Ras association domain family 1 isoform A.

of reaction mixture containing 2X EpiTect HRM Master Mix (Qiagen $\mathrm{GmbH}$ ), $10 \mu \mathrm{M}$ of each primer, $1 \mu \mathrm{l}$ of the diluted PCR product from the first step of MSP (5-10 ng per reaction) and RNase-free water to a final volume of $10 \mu \mathrm{l}$. Amplification consisted of an initial denaturation step at $95^{\circ} \mathrm{C}$ for $5 \mathrm{~min}$, followed by 45 cycles of the following steps: Denaturation for $10 \mathrm{sec}$ at $95^{\circ} \mathrm{C}$, annealing for $30 \mathrm{sec}$ at $61^{\circ} \mathrm{C}$ and extension for $10 \mathrm{sec}$ at $72^{\circ} \mathrm{C}$. To perform high-resolution melting analysis, the temperature was increased from 65 to $95^{\circ} \mathrm{C}$. The fluorescence of the binding fluorescent dye was measured continuously as the temperature was increased at a speed of $0.02^{\circ} \mathrm{C} / \mathrm{sec}$ and was plotted against the temperature.

Statistical analysis. All statistical tests were performed using $\mathrm{R}$ software (version 3.2.3) (35). Pearson's $\chi^{2}$ test with Yates continuity correction was used to test the compliance of the

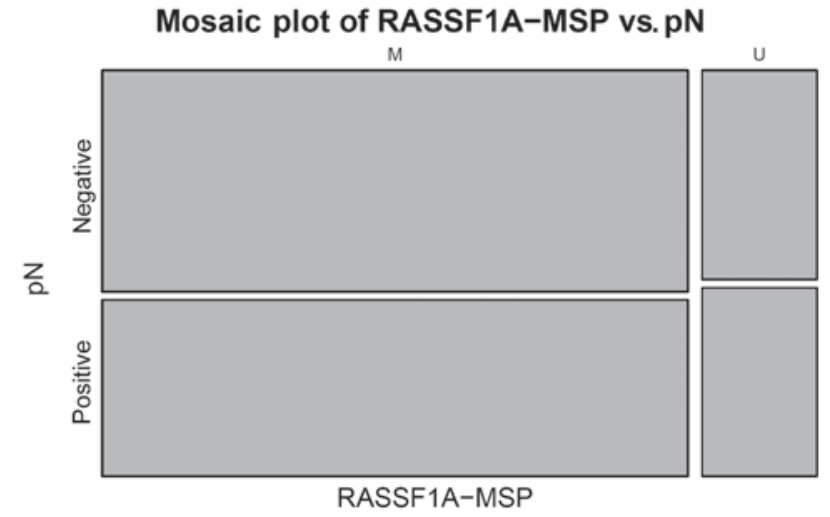

Figure 5. RASSF1A methylation profiles by MSP vs. positive or negative nodal status. The method allows the detection of methylated and unmethylated alleles where the extent of methylation can not be assessed. The rectangular area represents the number of samples in the particular category. MSP, methylation-specific polymerase chain reaction; $\mathrm{pN}$, pathological node; $\mathrm{M}$, methylated; U, unmethylated; RASSF1A, Ras association domain family 1 isoform A.

two methods used (MSP vs. MS-HRM) (Fig. 3). A multinomial logistic regression model was used to model the dependence of the methylation status levels derived from MS-HRM on the patients' clinicopathological characteristics. $\mathrm{P}<0.05$ was considered to indicate a statistically significant difference.

\section{Results}

Overall methylation results. The present study used MSP and MS-HRM to examine the methylation status of the promoter region of the RASSFIA gene in paraffin sections of 116 patients with breast cancer (Table I). Promoter region $\mathrm{CpG}$ hypermethylation was identified by MSP in 97 of $116(83.6 \%)$ primary tumors, while hypermethylation of RASSF1A was confirmed by MS-HRM in 107 (92.2\%) of cases.

MS-HRM for RASSF1A vs. lymph node status. The examined methylation status of RASSFIA included 64 breast tumor samples with stage N0 (negative lymph nodes) and 52 samples with stages N1, N2 and N3 (positive lymph nodes). The percentage of RASSF1A promoter methylation had a distinct range in tissues from patients with different lymph node metastatic stage. Based on the result of the multinomial logistic regression model, there was no significant difference between the frequency of RASSF1A promoter methylation among lymph node-positive and node-negative patients in general. However, unexpectedly, an association between $\mathrm{pNO}$ lymph node-negative status (without axillary metastases) and percentage of methylation was detected by MS-HRM in two groups of methylated alleles for RASSF1A: $\leq 50 \%$ methy lated group $(\mathrm{P}<0.05)$ and $>50 \%$ heterogeneous methylated group, where a stronger significant association was observed $(\mathrm{P}<0.0001)$ (Fig. 4). The MSP method did not identify any significant association (Fig. 5).

MS-HRM vs. MSP results. In the breast cancer samples, comparable results were obtained with the two assays used. More specifically, 48 samples were observed to be methylated and 4 unmethylated in lymph node-positive cases by 
MS-HRM, while 59 samples were observed to be methylated and 5 unmethylated in lymph node-negative cases. There were only small differences in the second method used. Only 43 samples were identified as methylated and 9 as unmethylated in lymph node-positive samples by MSP, while 54 samples were methylated and 10 samples were unmethylated in the lymph node-negative cases of breast cancer by MSP.

Statistical outputs. In the pN-negative group, the risk of having $>50 \%$ methylated alleles was identified as 8.6. In the $\mathrm{pN}$-positive group the risk was 9.25. The comparison of the risks, as estimated by the odds ratio, indicates that if a patient's nodal status changes from $\mathrm{pN}$ - to $\mathrm{pN}+$ then the risk of possessing $>50 \%$ methylated alleles increases by $7 \%$. This is in contrast with the results from the MSP, where moving from $\mathrm{pN}$-negative to $\mathrm{pN}$-positive decreases the risk of possessing $>50 \%$ methylated alleles by $6 \%$.

\section{Discussion}

The tumor-suppressor RASSF1A gene is the first identified RASSF family member that is frequently epigenetically inactivated in a wide range of cancer types (36). RASSF1A has been reported to be epigenetically inactivated in lung, ovary, bladder, kidney, endometrium and breast tumor tissue (37), and is methylated in $\sim 60-70 \%$ of breast cancers $(38,39)$. As a tumor-suppressor gene, RASSF1A regulates the activation of cell death (40), cell cycle (41) and microtubule formation (42). The methylation signature of RASSF $1 A$ is considered to be one among the earliest cellular changes in tumorigenesis $(38,39)$.

At present, DNA methylation is a widely studied epigenetic event (43). A previous study indicated that formalin-fixed, paraffin-embedded tissue is a valuable source for breast cancer biomarkers, for its biologic profiling or validation of certain signaling pathways $(44,45)$. Blocs can be also used for the detection of promoter hypermethylation as a diagnostic and prognostic biomarker in various cancers $(46,47)$. The methylation status of particular tumor-suppressor genes identified in paraffin-tissue samples displayed higher sensitivity for breast cancer origin than conventional biomarkers (43). Similarly, methylation occurs at the early stages of breast cancer development (48), and it may potentially reflect its metastatic potential into lymph nodes (49). Therefore, the present study used MSP and MS-HRM assays to identify a potential association between methylation of RASSF1A in breast cancer tissue and bilateral axillary nodal involvement. Bisulfite sequencing was used to validate the results.

Previous studies have identified RASSF1A promoter methylation as a potentially useful breast cancer biomarker for the presence of invasiveness of disease $(44,50)$. In addition, other studies have reported that methylation of the RASSF1A promoter provides an important prognostic information in operative breast tumors, and that methylation serves an important role in the clinical behavior of breast cancer (26). Although there is a significant effect of RASSF1A methylation on the biological characteristics of breast tumors, the association between methylation of $\mathrm{CpG}$ islands of this gene in breast tumor tissue obtained from paraffin sections and prognosis prediction by assessment of nodal affection has not been fully established yet. The prognostic value of aberrant methylation of RASSF1A in breast tumors has been demonstrated in cell-free DNA circulating in serum prior to therapy, and RASSF1A has been reported to be one among the 39 genes with prognostic significance in association with unfavorable development of the disease (45). According to that study, the results on RASSF1A methylation from paraffin sections also provide important prognostic information, since patients with RASSF1A methylation in the promoter region had a shorter disease-free interval than those with absence of methylation in this gene (45). It is likely that RASSF $1 A$ gene silencing due to promoter methylation causes deactivation of its tumor-suppressor role, and is therefore a possible contributor to short survival in patients with breast cancer.

Further studies demonstrated that RASSF1A methylation confers poor prognosis $(44,45,51)$ and significantly higher methylation with increasing tumor stage (from in situ to stage III) was observed, with a trend towards HER-2+ tumors, in women who were lymph node-positive at the time of diagnosis (52). Another study supported these results, since it observed that $R A S S F 1 A$ was frequently methylated in metastatic lymph nodes (53). Involvement of axillary lymph node metastasis is one of the single most important prognostic factors in the management of patients with primary breast cancer, and is considered to be a predictor of disease-free survival and overall survival in breast cancer $(54,55)$. Only 20-30\% of node-negative patients will develop recurrence within 10 years, compared with $70 \%$ of patients with axillary nodal involvement $(55,56)$. In general, patients with $\geq 4$ involved nodes at initial diagnosis have a worse outcome upon relapse than patients with negative lymph nodes (56). Furthermore, nodal metastasis is not only a marker of diagnosis at a later point in the natural history of breast cancer, but also a marker of an aggressive phenotype (57). Similarly, micrometastases have been associated with decreased survival in the early stage of breast cancer (9). Despite negative SLN-findings, metastases were detected in $7 \%$ of patients (58). In another study, 6 patients were identified with lymph node-negative, $\mathrm{ER}^{+} / \mathrm{HER}-2^{-}$breast cancer, and low 21-gene expression assay results (recurrence score of 0-17) were able to determine the risk of distant recurrence within 5 years of their breast cancer diagnosis (59).

The present study is in agreement with the above studies, since hypermethylation of RASSF1A was mostly observed in lymph node-positive cases. In addition, methylation occurred even in lymph node-negative cases, which suggests the onset of an epigenetic process in early breast carcinogenesis. Using the MS-HRM method, the results of the current study revealed that RASSF1A methylation correlated with SLN metastasis, while no significant association with SNL metastasis was observed using the MSP method. These findings suggest that the silencing of the RASSF1A gene is consistent with its role as a tumor suppressor in breast carcinogenesis. The present study provides methylation data in correlation with lymph node status in breast cancer, suggesting that promoter hypermethylation of the RASSF1A gene is a molecular predictor of early disease progression.

A great advantage of using MS-HRM is its ability to detect a methylated template in an unmethylated background, with a sensitivity similar to that of MSP. Furthermore, 
MS-HRM-based methylation screening is cost-, labor- and time-efficient, in contrast to direct bisulfite sequencing, which therefore, is unsuitable as a screening method. However, it still requires to determine the methylation status of individual $\mathrm{CpG}$ sites $(60,61)$.

Compared with MSP, the MS-HRM method provides comparable but not consistent results. The differences between MS-HRM and MSP can be explained by the different principles on which these methods are based (62). In MSP, a positive signal is obtained only in cases where the specific designed methylated primers bind a specific $\mathrm{CpG}$ island site in the sequence. However, it is known that different specimens may have different methylation sites in a specific sequence of the promoter region. For instance, if a sample is methylated in positions 2, 5 and 8, and the MSP primers are designed to discern methylation of $\mathrm{CpG}$ sites in positions 3, 4 and 7, MSP will provide a negative result, while MS-HRM will provide a positive result, since it is affected by the presence of any methylated $\mathrm{CpG}$ island that is located between the primers. On the other side, if the methylation sites that are recognized by the MSP primers are not included in the region amplified by the MS-HRM primers, a sample detected as positive by MSP will be detected as negative by MS-HRM (62). Furthermore, these differences were demonstrated in the results of the methylation analyses in the present study. In addition, the methylation status in the promoter region of the RASSF1A gene could be detected by MS-HRM with higher precision than by MSP.

In conclusion, RASSFIA is one of the most frequently hypermethylated tumor-suppressor genes detected in breast cancer, and the present results are consistent with those from previous studies $(25,26,36)$. These findings suggest the importance of RASSF1A methylation in breast cancer. Furthermore, the association of RASSF1A hypermethylation with known clinicopathological features, including lymph node metastasis, provides a better understanding of breast aggressiveness, and it could serve as an important prognostic marker during the treatment of breast cancer patients. Based on the current results, it can be assumed that heterogeneous methylation of the RASSF1A gene in breast carcinoma may indicate a potential connection with early-stage metastasis and invasion in ipsilateral axillary lymph nodes, even at a low level. However, this should be demonstrated by using detailed analytical methods, thus increasing the accuracy of this assumption. Such studies must focus mainly on geno-proteomic comparisons between node-positive and node-negative cases in order to examine the same events in metastatic tissue from the affected lymph nodes and the primary tumor. Particularly, based on the results from the IBCSG 23-01 and Z0011 studies, this biological activity and extension assessment is relevant for patient management, and thus axillary dissection could be avoided for patients with limited SN involvement $(63,64)$. Additionally, the results derived from such molecularly focused studies may lead to an improvement in the early detection of axillary metastatic spread of breast cancer in women compared with that of current diagnostic procedures.

\section{Acknowledgements}

The present study was supported by the Slovak Research and Development Agency (contract no. APVV-14-0815), the
Scientific Grant Agency of the Ministry of Education, Science, Research and Sport of the Slovak Republic and the Slovak Academy of Sciences (grant no. 1/0243/12) and the Comenius University in Bratislava (grant no. UK/156/2010).

\section{References}

1. Tao Z, Shi A, Lu C, Song T, Zhang Z and Zhao J: Breast cancer: epidemiology and etiology. Cell Biochem Biophys 72: 333-338, 2014.

2. Lester SC and Hicks DG: Diagnostic Pathology: Breast, 2nd edition. Elsevier Health Sciences, 2016.

3. Lyman GH, Temin S, Edge BS, Newman LA, Turner RR, Weaver DL, Benson AB III, Bosserman LD, Burstein HJ, Cody H III, et al: Sentinel lymph node biopsy for patients with early-stage breast cancer: American Society of Clinical Oncology clinical practice guideline update. J Clin Oncol 32: 1365-1383, 2014

4. Weigelt B, Hu Z, He X, Livasy C, Carey LA, Ewend MG Glas AM, Perou CM and Van't Veer LJ: Molecular portraits and 70-gene prognosis signature are preserved throughout the metastatic process of breast cancer. Cancer Res 65: 9155-9158, 2005.

5. Weigelt B, Peterse JL and van 't Veer LJ: Breast cancer metastasis: Markers and models. Nat Rev Cancer 5: 591-602, 2005.

6. Jones TI, Neboori H, Wu H, Yang Q, Haffty BG, Evans S, Higgins S and Moran MS: Are breast cancer subtypes prognostic for nodal involvement and associated with clinicopathologic features at presentation in early-stage breast cancer? Ann Surg Oncol 20: 2866-2872, 2013.

7. Byler S, Goldgar S, Heerboth S, Leary M, Housman G, Moulton K and Sarkar S: Genetic and epigenetic aspects of breast cancer progression and therapy. Anticancer Res 34: 1071-1077, 2014.

8. Weigel MT and Dowsett M: Current and emerging biomarkers in breast cancer: Prognosis and prediction. Endocr Relat Cancer 17: R245-R262, 2010.

9. de Boer M, van Dijck JA, Bult P, Borm GF and Tjan-Heijnen VC: Breast cancer prognosis and occult lymph node metastases, isolated tumor cells, and micrometastases. J Natl Cancer Inst 102: 410-425, 2010.

10. Yu M, Bardia A, Wittner BS, Stott SL, Smas ME, Ting DT, Isakoff SJ, Ciciliano JC, Wells MN, Shah AM, et al: Circulating breast tumor cells exhibit dynamic changes in epithelial and mesenchymal composition. Science 339: 580-584, 2013.

11. Harlow SP and Weaver DL: Diagnosis, staging and the role of sentinel lymph node biopsy in the nodal evaluation of breast cancer. http://www.uptodate.com/contents/overview-of-sentinel-lymphnode-biopsy-in-breast-cancer. Accessed December 12, 2016.

12. Veta M, Pluim JP, Van Diest PJ and Viergever MA: Breast cancer histopathology image analysis: A review. IEEE Trans Biomed Eng 61: 1400-1411, 2014.

13. Karakatsanis A, Christiansen PM, Fischer L, Hedin C, Pistioli L, Sund M, Rasmussen NR, Jørnsgård H, Tegnelius D, Eriksson S, et al: The Nordic SentiMag trial: A comparison of super paramagnetic iron oxide (SPIO) nanoparticles versus $\mathrm{Tc}(99)$ and patent blue in the detection of sentinel node (SN) in patients with breast cancer and a meta-analysis of earlier studies. Breast Cancer Res Treat 157: 281-294, 2016.

14. Upender S, Mohan $\mathrm{H}$, Hand $\mathrm{U}$ and Attri AK: Intraoperative evaluation of sentinel lymph nodes in breast carcinoma by imprint cytology, frozen section and rapid immunohistochemistry. Diagn Cytopathol 37: 871-875, 2009.

15. Soares EW, Nagai HM, Bredt LC, da Cunha AD Jr, Andrade RJ and Soares GV: Morbidity after conventional dissection of axillary lymph nodes in breast cancer patients. World J Surg Oncol 12: 67, 2014.

16. Wang Z, Wu LC and Chen JQ: Sentinel lymph node biopsy compared with axillary lymph node dissection in early breast cancer: A meta-analysis. Breast Cancer Res Treat 129: 675-689, 2011.

17. Gipponi M, Fregatti P, Garlaschi A, Murelli F, Margarino C, Depaoli F, Baccini P, Gallo M and Friedman D: Axillary ultrasound and Fine-Needle Aspiration Cytology in the preoperative staging of axillary node metastasis in breast cancer patients. Breast 30: 146-150, 2016.

18. Co M and Kwong A: Preoperative Sentinel Node Mapping in Sentinel Node Biopsy in Early Breast Cancers-Is It Cost-Effective? Clin Breast Cancer, 2016 (Epub ahead of print). 
19. Chirappapha P, Lohsiriwat V, Kongdan Y, Lertsithichai P, Sukarayothin T, Supsamutchai C, Talakhadze N and Zurrida S: Sentinel lymph node biopsy under local anesthesia in patients with breast cancer. Gland Surg 1: 151-155, 2012.

20. Luini A, Gatti G, Frasson A, Naninato P, Magalotti C, Arnone P, Viale G, Pruneri G, Galimberti V, De Cicco C and Veronesi U: Sentinel lymph node biopsy performed with local anesthesia in patients with early-stage breast carcinoma. Arch Surg 137: $1157-1160,2002$

21. Leidenius MH, Vironen JH, Heikkilä PS and Joensuu H: Influence of isolated tumor cells in sentinel nodes on outcome in small, node-negative (pT1N0M0) breast cancer. Ann Surg Oncol 17: 254-262,2010.

22. Gobardhan PD, Elias SG, Madsen EV, Bongers V, Ruitenberg HJ, Perre CI and Van Dalen T: Prognostic value of micrometastases in sentinel lymph nodes of patients with breast carcinoma: A cohort study. Ann Oncol 20: 41-48, 2009.

23. Cul'bová M, Lasabová Z, Stanclová A, Tilandyová P, Zúbor P, Fiolka R, Danko J and Visnovský J: Methylation of selected tumor-supressor genes in benign and malignant ovarian tumors. Ceska Gynekol 76: 274-279, 2011.

24. Fiolka R, Zubor P, Janusicova V, Visnovsky J, Mendelova A, Kajo K, Lasabova Z, Plank L and Danko J: Promoter hypermethylation of the tumor-suppressor genes RASSF1A, GSTP1 and CDH1 in endometrial cancer. Oncol Rep 30: 2878-2886, 2013.

25. Alvarez C, Tapia T, Cornejo V, Fernandez W, Muñoz A, Camus M, Alvarez M, Devoto L and Carvallo P: Silencing of tumor suppressor genes RASSF1A, SLIT2 and WIF1 by promoter hypermethylation in hereditary breast cancer. Mol Carcinog 52: 475-487, 2013.

26. Rauscher GH, Kresovich JK, Poulin M, Yan L, Macias V, Mahmoud AM, Al-Alem U, Kajdacsy-Balla A, Wiley EL, Tonetti D and Ehrlich M: Exploring DNA methylation changes in promoter, intragenic, and intergenic regions as early and late events in breast cancer formation. BMC Cancer 15: 816, 2015.

27. Lakhani SR, Ellis IO, Schnitt SJ, Tan PH and van de Vijver MJ (eds): WHO Classification of Tumours of the Breast, 4th edition. Lyon, IARC, 2012

28. Elston CW and Ellis IO: Pathological prognostic factors in breast cancer. I. The value of histological grade in breast cancer: experience from a large study with long-term follow-up. C. W. Elston \& I. O. Ellis. Histopathology 1991; 19; 403-410. Histopatology 41: $151-153,2002$

29. Edge SB and Compton CC: The American Joint Committee on Cancer: the 7th edition of the AJCC cancer staging manual and the future of TNM. Ann Surg Oncol. 17: 1471-1474, 2010.

30. Hammond ME, Haves DF, Wolff AC, Mangu PB and Temin S: American Society of Clinical Oncology/College of American Pathologists guideline recommendations for immunohistochemical testing of estrogen and progesterone receptors in breast cancer. J Oncol Pract 6: 195-197, 2010.

31. Wolff AC, Hammond ME, Hicks DG, Dowsett M, McShane LM, Allison KH, Allred DC, Bartlett JM, Bilous M, Fitzgibbons $\mathrm{P}$, et al: Recommendations for human epidermal growth factor receptor 2 testing in breast cancer: American Society of Clinical Oncology/College of American Pathologists clinical practice guideline update. Arch Pathol Lab Med 138: 241-256, 2014.

32. Wolff AC, Hammond ME, Hicks DG, Dowsett M, McShane LM, Allison KH, Allred DC, Bartlett JM, Bilous M, Fitzgibbons $\mathrm{P}$, et al: Recommendations for human epidermal growth factor receptor 2 testing in breast cancer: American Society of Clinical Oncology/College of American Pathologists clinical practice guideline update. J Clin Oncol 31: 3997-4013, 2013.

33. Huang KT, Mikeska T, Li J, Takano EA, Millar EK, Graham PH, Boyle SE, Campbell IG, Speed TP, Dobrovic A and Fox SB: Assessment of DNA methylation profiling and copy number variation as indications of clonal relationship in ipsilateral and contralateral breast cancers to distinguish recurrent breast cancer from a second primary tumour. BMC Cancer 15: 669, 2015

34. Wojdacz TK and Dobrovic A: Methylation-sensitive high resolution melting (MS-HRM): A new approach for sensitive and high-throughput assessment of methylation. Nucleic Acids Res 35: e41, 2007.

35. R Core Team . R: A language and environment for statistical computing. R Foundation for Statistical Computing, Vienna, Austria. URL https://www.R-project.org/. 2015.
36. Dammann R, Schagdarsurengin U, Seidel C, Strunnikova M, Rastetter M, Baier K and Pfeifer GP: The tumor suppressor RASSF1A in human carcinogenesis: An update. Histol Histopathol 20: 645-663, 2005

37. Agathanggelou A, Honorio S, Macartney DP, Martinez A, Dallol A, Rader J, Fullwood P, Chauhan A, Walker R, Shaw JA, et al: Methylation associated inactivation of RASSF1A from region $3 \mathrm{p} 21.3$ in lung, breast and ovarian tumours. Oncogene 20: 1509-1518, 2001 .

38. Agathanggelou A, Cooper WN and Latif F: Role of the Ras-association domain family 1 tumor suppressor gene in human cancers. Cancer Res 65: 3497-3508, 2005.

39. Dammann R, Yang G and Pfeifer GP: Hypermethylation of the cpG island of Ras association domain family 1A (RASSF1A), a putative tumor suppressor gene from the 3 p21. 3 locus, occurs in a large percentage of human breast cancers. Cancer Res 61: 3105-3109, 2001

40. Ghazaleh HA, Chow RS, Choo SL, Pham D, Olesen JD, Wong RX, Onyskiw C and Baksh S: 14-3-3 mediated regulation of the tumor suppressor protein, RASSF1A. Apoptosis 15: 117-127, 2010.

41. Shivakumar L, Minna J, Sakamaki T, Pestell R and White MA: The RASSF1A tumor suppressor blocks cell cycle progression and inhibits cyclin D1 accumulation. Mol Cell Biol 22: 4309-4318, 2002

42. Dallol A, Agathanggelou A, Fenton SL, Ahmed-Choudhury J, Hesson L, Vos MD, Clark GJ, Downward J, Maher ER and Latif F: RASSF1A interacts with microtubule-associated proteins and modulates microtubule dynamics. Cancer Res 64 4112-4116, 2004

43. Duffy MJ, Sturgeon CM, Sölétormos G, Barak V, Molina R, Hayes DF, Diamandis EP and Bossuyt PM: Validation of new cancer biomarkers: A position statement from the European group on tumor markers. Clin Chem 61: 809-820, 2015.

44. Lewis CM, Cler LR, Bu DW, Zöchbauer-Müller S, Milchgrub S, Naftalis EZ, Leitch AM, Minna JD and Euhus DM: Promoter hypermethylation in benign breast epithelium in relation to predicted breast cancer risk. Clin Cancer Res 11: 166-172, 2005.

45. Müller HM, Widschwendter A, Fiegl H, Ivarsson L, Goebel G, Perkmann E, Marth C and Widschwendter M: DNA methylation in serum of breast cancer patients: An independent prognostic marker. Cancer Res 63: 7641-7645, 2003.

46. Marino AL, Evangelista AF, Vieira RA, Macedo T, Kerr LM, Abrahão-Machado LF, Longatto-Filho A, Silveira HC and Marques MM: MicroRNA expression as risk biomarker of breast cancer metastasis: A pilot retrospective case-cohort study. BMC Cancer 14: 739, 2014.

47. Sequeiros T, García M, Montes M, Oliván M, Rigau M, Colás E, de Torres I, Morote J, Reventós J and Doll A: Molecular markers for prostate cancer in formalin-fixed paraffin-embedded tissues. Biomed Res Int 2013: 283635, 2013.

48. Van Hoesel AQ, Sato Y, Elashoff DA, Turner RR, Giuliano AE, Shamonki JM, Kuppen PJ, van de Velde CJ and Hoon DS: Assessment of DNA methylation status in early stages of breast cancer development. Br J Cancer 108: 2033-2038, 2013.

49. Schrijver WA, Jiwa LS, van Diest PJ and Moelans CB: Promoter hypermethylation profiling of distant breast cancer metastases. Breast Cancer Res Treat 151: 41-55, 2015.

50. Fackler MJ,McVeigh M, Evron E, GarrettE, Mehrotra J, Polyak K, Sukumar S and Argani P: DNA methylation of RASSF1A, HIN-1, RAR- $\beta$, Cyclin D2 and Twist in in situ and invasive lobular breast carcinoma. Int J Cancer 107: 970-975, 2003.

51. Fackler MJ, McVeigh M, Mehrotra J, Blum MA, Lange J, Lapides A, Garrett E, Argani P and Sukumar S: Quantitative multiplex methylation-specific PCR assay for the detection of promoter hypermethylation in multiple genes in breast cancer. Cancer Res 64: 4442-4452, 2004.

52. Swift-Scanlan T, Vang R, Blackford A, Fackler MJ and Sukumar S. Methylated genes in breast cancer: Associations with clinical and histopathological features in a familial breast cancer cohort. Cancer Biol Ther 11: 853-865, 2011

53. Feng W, Orlandi R, Zhao N, Carcangiu ML, Tagliabue E, Xu J, Bast RC Jr and Yu Y: Tumor suppressor genes are frequently methylated in lymph node metastases of breast cancers. BMC Cancer 10: 378, 2010.

54. Rouzier R, Extra JM, Klijanienko J, Falcou MC, Asselain B, Vincent-Salomon A, Vielh P and Bourstyn E: Incidence and prognostic significance of complete axillary downstaging after primary chemotherapy in breast cancer patients with T1 to T3 tumors and cytologically proven axillary metastatic lymph nodes. J Clin Oncol 20: 1304-1310, 2002. 
55. Fisher ER, Anderson S, Redmond C and Fisher B: Pathologic findings from the national surgical adjuvant breast project protocol B-06: 10-year pathologic and clinical prognostic discriminants. Cancer 71: 2507-2514, 1993.

56. Fitzgibbons PL, Page DL, Weaver D, Thor AD, Allred DC, Clark GM, Ruby SG, O'Malley F, Simpson JF and Connolly JL, et al: Prognostic factors in breast cancer: College of American Pathologists consensus statement 1999. Arch Pathol Lab Med 124: 966-978, 2000.

57. Jatoi I, Hilsenbeck SG, Clark GM and Osborne CK: Significance of axillary lymph node metastasis in primary breast cancer. J Clin Oncol 17: 2334-2340, 1999.

58. Weiss M, Meyer M, Siegert S, Bartenstein P and Pfluger T: Metastases in patients with breast cancer despite of negative sentinel lymph node. Has the concept to be changed? Nuklearmedizin 52: 14-20, 2013.

59. Wen HY, Krystel-Whittemore M, Patil S, Pareja F, Bowser ZL, Dickler MN, Norton L, Morrow M, Hudis CA and Brogi E: Breast carcinoma with an Oncotype Dx recurrence score < 18: Rate of distant metastases in a large series with clinical follow-up. Cancer 123: 131-137, 2017.

60. Wojdacz TK, Møller TH, Thestrup BB, Kristensen LS and Hansen LL: Limitations and advantages of MS-HRM and bisulfite sequencing for single locus methylation studies. Expert Rev Mol Diagn 10: 575-580, 2010.
61. Wojdacz TK, Windeløv JA, Thestrup BB, Damsgaard TE, Overgaard $\mathrm{J}$ and Hansen L: Identification and characterization of locus-specific methylation patterns within novel loci undergoing hypermethylation during breast cancer pathogenesis. Breast Cancer Res 16: R17: 2014.

62. Dobrovic A: Analysis of DNA methylation in clinical samples: Methods and applications. In molecular pathology in cancer research (pp. 261-277) Springer New York 2016.

63. Galimberti V, Cole BF, Zurrida S, Viale G, Luini A, Veronesi P, Baratella P, Chifu C, Sargenti M, Intra M, et al: Axillary dissection versus no axillary dissection in patients with sentinel-node micrometastases (IBCSG 23-01): A phase 3 randomised controlled trial. Lancet Oncol 14: 297-305, 2013

64. Giuliano AE, Ballman K, McCall L, Beitsch P, Whitworth PW, Blumencranz P, Leitch AM, Saha S, Morrow M and Hunt KK: Locoregional Recurrence After Sentinel Lymph Node Dissection With or Without Axillary Dissection in Patients With Sentinel Lymph Node Metastases: Long-term Follow-up From the American College of Surgeons Oncology Group (Alliance) ACOSOG Z0011 Randomized Trial. Ann Surg 264: 413-420, 2016. 